\title{
REVISTA SEMILLEROS DE INVESTIGACIÓN, UN APORTE A LA FORMACIÓN EN INVESTIGACIÓN.
}

El mundo esta avanzando a ritmos muy rápidos, muchos dirán que ese avance no se esta dando por el camino correcto, otros seguramente afirmaran que ese camino es el correcto, pero el camino que si hemos dejado o por lo menos la frase que ya no escuchamos tanto o casi no pronunciamos, es sociedad industrial, ahora oímos y leemos en muchos lugares la frase sociedad de conocimiento, esta sociedad de conocimiento tiene como base fundamental la universidad ya que esta es la llamada a generar conocimiento, y así como a cambiado el mundo, la universidad tiene que cambiar en pro de generar no solo mas profesionales, sino profesionales mas inquietos que sean capaces de resolver problemas concretos de nuestra realidad, esta no es una tarea fácil, pues transformar la universidad no se puede hacer de forma inmediata, ya que necesitamos diseñar y/o aplicar nuevas metodologías que nos permitan romper el esquema del estudiante y profesor tradicional que repite constantemente $y$ porque no decirlo de memoria el manual de texto.

Queremos una comunidad académica en nuestra universidad que propicie la inquietud, la búsqueda de conocimiento, las preguntas y sobre todo las respuestas que el mundo esta pidiendo a gritos, incluso a ruegos para generar cambios en muchos aspectos que afectan nuestro bienestar, nuestro entorno y nuestro planeta.

Sin duda la investigación que desarrollan profesores y estudiantes, es una forma de romper el esquema tradicional de universidad profesionalizante, ahora en la universalidad de la universidad no todo debe ser igual y muchos menos todos debemos caminar por el mismo camino, debemos avanzar y trazar nuevos caminos que nos permitan cumplir nuestros objetivos misionales.

Consideramos que la investigación que deseamos desarrollar es aquella que nos permita interactuar con nuestros contextos, con nuestras personas, con nuestros comportamientos, en fin, con lo tangible e intangible, con lo imaginario y lo real, pero sobre todo debe ser aquella que permita resolver nuestros problemas, nuestras preguntas y consideraciones que podemos tener un mejor presente y futuro, ya que del pasado solo podemos aprender. 
La UPTC no solo cuenta con recursos limitados, problema que abunda en cualquier lugar del mundo, y del que nos sobra a todos. Obviamente lo anterior no puede ser argumento para conformarnos, por el contrario debe ser una explicación que corrobore nuestra intención de tener una universidad generadora de conocimiento que solucione las múltiples dificultades de nuestra sociedad. Ya hemos entendido que generar conocimiento no es fácil cuando no se cuenta con los recursos necesarios, y que si los tuviéramos seria ilógico pretender ir a la luna, cuando tenemos preguntas y dificultades más grandes que la luna, por resolver. Nuestra universidad también cuenta con una gran cantidad de estudiantes y profesores que han constituido grupos de investigación que han aportado valiosos resultados a la UPTC y sociedad, de igual forma han generado el proceso de creación de semilleros de investigación. Estos semilleros de investigación se han denomina así seguramente porque son el inicio de un proceso de formación en investigación que culminara en lo personal seguramente en reconocimientos académicos y en lo colectivo en un mejor entendimiento de nuestro contexto o seguramente en un mejor bienestar para la sociedad.

La revista semilleros de investigación nace precisamente como aporte a ese proceso de formación del investigador, como demostración que el trabajo en equipo puede consolidar objetivos de cualquier tamaño, como un espacio que permitirá impulsar la producción escrita de todos los estudiantes de la UPTC que han iniciado un proceso de formación de investigación en los semilleros de investigación. En este sentido nuestras pretensiones no son otras que decir que la escritura no es una actividad exclusiva de literatos y poetas, sino que por el contrario es una actividad humana, de todos los estudiantes que quieren ir mas haya de las palabras, que se lleva el viento y el olvido, y escribe para ser leído, criticado, elogiado en fin, para caer en el circulo virtuoso de la lectura y la escritura de la pregunta y desafío de responder la pregunta. Aunque puede ser poco en masa, la revista semilleros de investigación es gigante en ese cambio que queremos dar hacia la sociedad del conocimiento, hacia ese universo por descubrir, por mejorar, por transformar, por cambiar, quizás más universos por descubrir... Esta revista que hoy presentamos a la comunidad universitaria, esta dando sus primeros pasos, con sus propios tropiezos, con sus pasos grandes, pero sobre todo con la firmeza de recorrer mucho camino en el tiempo.

Hoy y siempre estaremos buscando la forma de contribuir a este universo que llamamos universidad, sociedad, país, mundo. Estamos convencidos que la mejor forma de generar respuestas a preguntas, a problemas de cualquier orden es la investigación y si la esencia de la universidad es la búsqueda de 
conocimiento, de verdad, estamos trabajando en el proyecto correcto que hemos llamado revista semilleros de investigación, este proyecto interminable como las preguntas, será un ingrediente a la sabia que nutre la búsqueda de respuestas de conocimiento de verdad en la Universidad Pedagógica y Tecnológica de Colombia.

VICTOR GAMBOA

Editor

Revista Semilleros de Investigación.

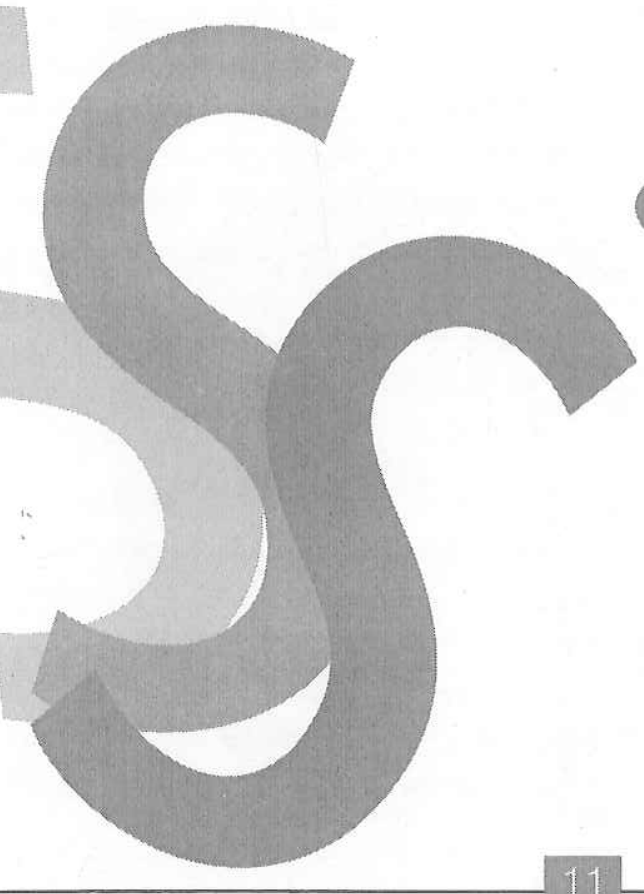

